\title{
PERBANDINGAN APROKSIMASI VARIASIONAL ANTARA DUA ANSATZ UNTUK SOLUSI SOLITON CERAH INTERSITE PADA PERSAMAAN SCHRÖDINGER DISKRIT NONLINIER DENGAN PENAMBAHAN PARAMETER DRIVING
}

\author{
NOVERINA ALFIANY, MAHDHIVAN SYAFWAN, MUHAFZAN \\ Program Studi Magister Matematika, \\ Fakultas Matematika dan Ilmu Pengetahuan Alam, Universitas Andalas, \\ Kampus UNAND Limau Manis Padang, Indonesia, \\ noverinaalfiany_1121@s2.mathunand.ac.id
}

\begin{abstract}
Abstrak. Persamaan Schrödinger Diskrit Nonlinier (SDNL) dengan penambahan parameter driving merupakan model persamaan yang lebih realistis dalam memodelkan fenomena perambatan serat optik. Hal yang menarik dari Persamaan SDNL ini adalah eksistensi solusi soliton yang dimilikinya. Dalam penelitian ini dikaji tentang hampiran solusi soliton cerah intersite dari persamaan SDNL dengan menggunakan metode aproksimasi variasional (AV) untuk dua ansatz yang berbeda, katakanlah ansatz (1) dan ansatz (2). Solusi analitik dari kedua ansatz tersebut dibandingkan dengan solusi numeriknya. Diperoleh bahwa AV sangat baik dalam menghampiri solusi soliton untuk nilai konstanta coupling yang semakin kecil serta nilai parameter driving yang semakin besar. Hasil AV dari kedua ansatz juga menunjukkan bahwa hampiran solusi yang diperoleh sama bagusnya dalam menghampiri solusi numeriknya.
\end{abstract}

Kata Kunci: Persamaan SDNL, metode Aproksimasi Variasional, soliton, ansatz, parameter driving, konstanta coupling

\section{Pendahuluan}

Persamaan Schrödinger Diskrit Nonlinier (SDNL) merupakan salah satu model persamaan yang sering dijumpai pada berbagai aplikasi penting. Beberapa diantaranya adalah dinamika sistem osilator tak harmonik terikat (coupled), perambatan serat optik pada pandu gelombang nonlinier terikat, dan dinamika kondensasi BoseEinstein (Bose-Einstein Condensation (BEC)) yang terperangkap dalam potensial periodik [1].

Salah satu hal yang paling menarik pada Persamaan SDNL ini adalah eksistensi solusi soliton yang dimilikinya. Soliton merupakan gelombang nonlinier terlokalisasi yang dapat mempertahankan bentuknya ketika merambat pada kecepatan konstan, walaupun setelah berinteraksi dengan soliton lainnya [2], [3]. Dalam konteks aplikasi pada teknologi komunikasi berbasis serat optik, soliton dapat direkayasa sebagai pembawa informasi yang dapat merambat pada media dengan jarak tempuh yang sangat jauh tanpa ada gangguan yang berarti. Fenomena ini sangat penting dalam perkembangan teknologi informasi dan komunikasi masa depan. 
Persamaan SDNL merupakan salah satu persamaan yang nonintegrable, sehingga salah satu cara yang dapat dilakukan untuk menyelesaikan persamaan tersebut adalah dengan mengembangkan metode analitik untuk menghampiri solusinya. Salah satu metode yang cukup dikenal dan sering digunakan adalah metode Aproksimasi Variasional (untuk selanjutnya Aproksimasi Variasional akan disingkat dengan AV).

Chong dkk. [4] telah mengkaji secara matematis bahwa fungsi ansatz (penduga) untuk soliton diskrit dengan parameter yang lebih banyak memberikan aproksimasi yang lebih akurat. Pada [5], metode AV telah digunakan untuk menentukan hampiran solusi soliton cerah (bright soliton) bertipe onsite pada Persamaan SDNL dengan penambahan parameter driving untuk kasus limit anti-continuum. Pada [11] telah ditunjukkan bahwa prediksi solusi soliton yang diperoleh dari metode AV sangat akurat ketika dibandingkan dengan hasil-hasil numerik. Dalam paper ini, kajian pada [5] akan dilanjutkan untuk solusi soliton cerah bertipe intersite dengan membandingkan dua ansatz.

\section{Persamaan Model dan Analisis Awal}

Dalam [6] diberikan persamaan SDNL dengan penambahkan parameter driving sebagai berikut.

$$
i \dot{\psi}_{n}=-\varepsilon \Delta_{2} \psi_{n}+\gamma \bar{\psi}_{n} e^{i \Lambda t} \pm\left|\psi_{n}\right|^{2} \psi_{n}
$$

di mana $\psi_{n} \equiv \psi_{n}(t) \in \mathbb{C}$ adalah fungsi gelombang pada waktu $t \in \mathbb{R}^{+}$dan site $n \in \mathbb{Z}, \dot{\psi}_{n}$ menyatakan turunan $\psi_{n}$ terhadap $t, \varepsilon>0$ merepresentasikan konstanta pengikat (coupling constant) antara dua site yang bersebelahan, $\Delta_{2} \psi_{n}=\psi_{n+1}-$ $2 \psi_{n}+\psi_{n-1}$ adalah Laplacian diskrit pada dimensi satu, $\gamma$ menyatakan koefisien driving dengan frekuensi $\Lambda$ dan $\bar{\psi}_{n}$ merupakan kompleks konjugat dari $\psi_{n}$.

Solusi soliton diskrit stasioner dari (2.1) ditentukan dengan menggunakan transformasi $\psi_{n}(t)=u_{n} e^{i \frac{\Lambda t}{2}}$, sehingga diperoleh

$$
-\varepsilon\left(u_{n+1}+u_{n-1}\right)+\Omega u_{n}+\gamma \bar{u}_{n} \pm\left|u_{n}\right|^{2} u_{n}=0,
$$

di mana $\Omega=\frac{\Lambda}{2}+2 \varepsilon$.

Persamaan (2.1) pertama kali dikaji oleh Hennig [6]. Kajian terhadap persamaan ini kemudian ditinjau lagi oleh Susanto dkk. [7] dan Syafwan dkk. [8], di mana diperoleh hasil bahwa parameter driving tidak hanya menstabilkan soliton diskrit cerah onsite namun juga dapat menstabilkan soliton diskrit cerah intersite.

Persamaan SDNL stasioner bertipe focusing dengan penambahan parameter driving diberikan oleh

$$
-\varepsilon\left(u_{n+1}+u_{n-1}\right)+\Omega u_{n}+\gamma \bar{u}_{n}-\left|u_{n}\right|^{2} u_{n}=0 .
$$

Perhatikan bahwa parameter $\Omega$ pada (2.3) dapat dinormalkan menjadi 1 dengan menggunakan transformasi

$$
u_{n} \rightarrow u_{n} \sqrt{\Omega}, \varepsilon \rightarrow \varepsilon \Omega, \gamma \rightarrow \gamma \Omega
$$


Dengan demikian, tanpa mengurangi keumuman, $\Omega$ pada (2.3) dapat diganti menjadi 1, sehingga (2.3) menjadi

$$
-\varepsilon\left(u_{n+1}+u_{n-1}\right)+u_{n}+\gamma \bar{u}_{n}-\left|u_{n}\right|^{2} u_{n}=0 .
$$

Pada paper ini, secara khusus akan dikaji solusi soliton cerah intersite dari (2.5) dengan syarat batas

$$
u_{n} \rightarrow 0 \text { bilamana } n \rightarrow \pm \infty \text {. }
$$

Pada kasus $\gamma=0,(2.5)$ memiliki invarian gauge atau phase, yaitu jika dikenakan suatu transformasi $u_{n} \rightarrow u_{n} e^{i \theta}$ untuk setiap nilai $\theta \in \mathbb{R}$ maka (2.5) tidak berubah. Pada kasus $\gamma \neq 0,(2.5)$ tidak lagi memiliki invarian gauge karena terdapat suku kompleks konjugat. Namun jika dikenakan transformasi $u_{n} \rightarrow u_{n} e^{i \theta}$ untuk nilai $\theta=\pi+2 k \pi$ dan $\theta=-\frac{\pi}{2}+2 k \pi$ dengan $k \in \mathbb{Z},(2.5)$ secara berturut-turut memiliki refleksi simetri

$$
u_{n} \rightarrow-u_{n}
$$

dan

$$
u_{n} \rightarrow i u_{n}, \quad \gamma \rightarrow-\gamma
$$

Dari transformasi (2.8) dapat disimpulkan bahwa nilai $\gamma$ pada (2.5) dapat dipilih untuk nilai $\gamma>0$.

Sebagaimana yang sudah disebutkan sebelumnya, jika $\gamma=0$ maka solusi soliton pada (2.5) yang memenuhi kondisi (2.6) bernilai riil [9], [10]. Sedangkan pada saat $\gamma>0$ terdapat dua kemungkinan solusi, yaitu solusi bernilai riil (dengan syarat $1+\gamma>0$ ) atau imajiner murni (dengan syarat $1-\gamma>0$ ), di mana solusi bernilai imajiner murni selalu tidak stabil [11]. Oleh karena itu, yang ditinjau dalam paper ini hanya solusi yang bernilai riil saja, sehingga (2.5) dapat disederhanakan menjadi

$$
-\varepsilon\left(u_{n+1}+u_{n-1}\right)+(\gamma+1) u_{n}-u_{n}^{3}=0 .
$$

\section{Aproksimasi Variasional}

Pada bab ini akan diturunkan formulasi aproksimasi variasional (AV) untuk solusi soliton stasioner pada (2.9). Perhatikan bahwa Lagrangian dari (2.9) diberikan oleh

$$
L=\sum_{n=-\infty}^{\infty} 2 \varepsilon\left(u_{n} u_{n+1}\right)-(\gamma+1) u_{n}^{2}+\frac{1}{2} u_{n}^{4} .
$$

Pada saat $\varepsilon=0,(2.9)$ memiliki solusi eksak $\left.u_{n}\right|_{\varepsilon=0}=0, \pm \sqrt{\gamma+1}$. Untuk soliton cerah tipe intersite, struktur konfigurasinya adalah

$$
\left.u_{n}\right|_{\varepsilon=0}= \begin{cases}\sqrt{\gamma+1}, & n=0,1 \\ 0 & , n \neq 0,1 .\end{cases}
$$

Dalam hal ini, nilai $\left.u_{n}\right|_{\varepsilon=0}=-\sqrt{\gamma+1}$ diabaikan karena transformasi $(2.7)$. 


\subsection{Ansatz (1)}

Pada subbab ini akan dibahas perhitungan AV dengan menggunakan ansatz [4].

$$
u_{n}^{(1)}= \begin{cases}A e^{a(n+1)} & , n \leq-1 \\ B & , n=0,1 \\ A e^{-a(n-2)} & , n \geq 2\end{cases}
$$

di mana $A, B$ dan a adalah parameter variasional yang bernilai riil.

Dengan mensubstitusikan ansatz pada (3.3) ke (3.1) dan menyelesaikan bentuk penjumlahannya, diperoleh Lagrangian efektif sebagai berikut.

$$
L_{e f f}^{(1)}=\frac{A^{4}}{1-e^{-4 a}}-\frac{2 e^{a}\left(e^{a}+e^{a} \gamma-2 \varepsilon\right) A^{2}}{-1+e^{2 a}}+4 \varepsilon A B+2 B^{2}(\varepsilon-\gamma)+B^{4} .
$$

Berdasarkan prinsip variasional, Lagrangian efektif $L_{\text {eff }}$ mencapai nilai kritis pada Persamaan Euler-Lagrange

$$
\frac{\partial L_{e f f}^{(1)}}{\partial A}=\frac{\partial L_{e f f}^{(1)}}{\partial B}=\frac{\partial L_{e f f}^{(1)}}{\partial a}=0 .
$$

Dengan mensubstitusikan (3.4) ke (3.5), diperoleh sistem persamaan

$$
\begin{aligned}
0= & \frac{4 A^{3}}{1-e^{-4 a}}-\frac{4 A e^{a}\left(e^{a}+e^{a} \gamma-2 \varepsilon\right)}{-1+e^{2 a}}+4 \varepsilon B, \\
0= & \varepsilon(A+B)-(\gamma+1) B+B^{3}, \\
0=- & \varepsilon\left(e^{a}-2 e^{-a}+e^{3 a}-2 e^{-3 a}+e^{-7 a}+e^{-5 a}\right) \\
& \quad+(\gamma+1)\left(e^{2 a}-2 e^{-2 a}+e^{-6 a}\right)+A^{2}\left(2 e^{2 a}-e^{-4 a}-1\right) .
\end{aligned}
$$

\subsection{Ansatz(2)}

Pada subbab ini perhitungan AV menggunakan ansatz

$$
u_{n}^{(2)}= \begin{cases}A & , n=0, \\ B & , n=1, \\ C e^{a\left|n-\frac{1}{2}\right|} & ,-1 \leq n \leq 2,\end{cases}
$$

di mana $A, B, C$ dan $a$ adalah parameter variasional yang bernilai riil.

Selanjutnya (3.9) disubstitusikan ke (3.1). Setelah menyelesaikan bentuk penjumlahannya, diperoleh Lagrangian efektif,

$$
\begin{aligned}
L_{e f f}^{(2)}= & \left(-4-4 \gamma-2 e^{2 a} \gamma-2 e^{2 a}+8 e^{a} \varepsilon+C^{2} e^{5 a}+C^{2} e^{-a}-2 e^{-2 a}-2 \gamma e^{-2 a}+8 \varepsilon e^{-a}\right) \\
& \frac{C^{2}}{2\left(e^{4 a}-1\right)} e^{-a}+2 \varepsilon C e^{\frac{-3 a}{2}} A-C^{2} e^{\frac{-3 a}{2}{ }^{2}}-\gamma C^{2} e^{\frac{-3 a}{2}}+\frac{1}{2} C^{4} e^{\frac{-3 a}{2}}{ }^{4} \\
& +2 \varepsilon A B-A^{2}-\gamma A^{2}+\frac{1}{2} A^{4}+2 \varepsilon B C e^{\frac{-3 a}{2}}-B^{2}-\gamma B^{2}+\frac{1}{2} B^{4} .
\end{aligned}
$$

Sebagaimana langkah sebelumnya, Lagrangian efektif $L_{\text {eff }}$ mencapai nilai kritis pada Persamaan Euler-Lagrange

$$
\frac{\partial L_{e f f}^{(2)}}{\partial A}=\frac{\partial L_{e f f}^{(2)}}{\partial B}=\frac{\partial L_{e f f}^{(2)}}{\partial C}=\frac{\partial L_{e f f}^{(2)}}{\partial a}=0
$$


sehingga diperoleh sistem persamaan

$$
\begin{aligned}
0= & \varepsilon\left(B+C e^{\frac{-3 a}{2}}\right)-A\left(1+\gamma-A^{2}\right), \\
0= & \varepsilon\left(A+C e^{\frac{-3 a}{2}}\right)-B\left(1+\gamma-B^{2}\right), \\
0= & C\left(e^{a}(-\gamma-1)+e^{-2 a}\left(C^{2}+2 \varepsilon\right)+e^{-a}(-\gamma-1)+2 \varepsilon\right)- \\
& \varepsilon e^{\frac{-3 a}{2}}-\frac{A}{4}+A \varepsilon e^{\frac{5 a}{2}}, \\
0= & C\left(e^{a}(\gamma+1)+e^{-2 a}\left(C^{2}+4 \varepsilon\right)+e^{-a}(-\gamma-1)+e^{2 a}\left(-12 \varepsilon-3 C^{2}\right)+\right. \\
& \left.e^{3 a}(5+5 \gamma)-8 e^{4 a} \varepsilon+e^{5 a}(3 \gamma+3)\right)-3 A \varepsilon\left(e^{\frac{-3 a}{2}}+2 e^{\frac{5 a}{2}}-e^{\frac{13 a}{2}}\right) .
\end{aligned}
$$

\section{Perbandingan Solusi AV dengan Solusi Numerik}

Pada bab ini, solusi soliton intersite pada (2.9), yang dihitung secara numerik dengan menggunakan metode Newton-Raphson, akan dibandingkan dengan hampiran solusi AV menggunakan dua ansatz yang berbeda.

Sebagai ilustrasi, pada Gambar 4.1 diperlihatkan perbandingan antara dua solusi yang dicari dari perhitungan numerik dan aproksimasi variasional untuk parameter driving $\gamma=0,02 ; 0,7$ dan konstanta pengikat $\varepsilon=0,0 ; 0,2 ; 0,45$. Setelah memperoleh solusi dari sistem (3.6) - (3.8) dan (3.12) - (3.15) untuk nilai-nilai $\varepsilon$ dan $\gamma$, diperoleh hasil-hasil parameter variasional (lihat Gambar 4.1).

Secara umum dapat dilihat bahwa perbandingan kedua hampiran solusi soliton AV dengan solusi numerik memiliki kesesuaian yang sangat bagus untuk nilai $\varepsilon$ yang semakin kecil dan nilai $\gamma$ yang semakin besar. Hampiran solusi dari kedua ansatz juga sama baiknya dalam menghampiri solusi numeriknya.

Untuk mengkonfirmasi lebih lanjut kesesuaian antara kedua hampiran solusi soliton AV dengan solusi numerik, pada Gambar 4.2 diplot norm $l^{2}$ dari kedua hampiran solusi soliton AV dengan solusi numerik sebagai fungsi terhadap $\varepsilon$ untuk nilai $\gamma=0,02$ dan $\gamma=0,7$. Berdasarkan gambar tersebut dapat disimpulkan bahwa solusi soliton AV sangat baik dalam menghampiri solusi soliton untuk $\varepsilon$ yang semakin kecil.

\section{Kesimpulan}

Hasil aproksimasi variasional (AV) yang dikembangkan untuk solusi soliton cerah intersite dengan dua ansatz yang berbeda pada penelitian ini sangat baik dalam menghampiri solusi soliton yang diperoleh secara numerik untuk $\varepsilon$ yang semakin kecil. Di samping itu, ditunjukkan pula bahwa solusi AV semakin baik untuk nilai $\gamma$ yang semakin besar.

\section{Daftar Pustaka}

[1] A. Trombettoni dan A. Smerzi, 2001, Discrete solitons and breathers with dilute Bose-Einstein condensates, Phys. Rev. Lett. 86 : 2353.

[2] A. Scott, 2005, Encyclopedia of Nonlinear Science, Routledge, New York and London.

[3] P. G. Drazin dan R. S. Johnson, 1989, Solitons: An Introduction, Cambridge University Press, Cambridge. 

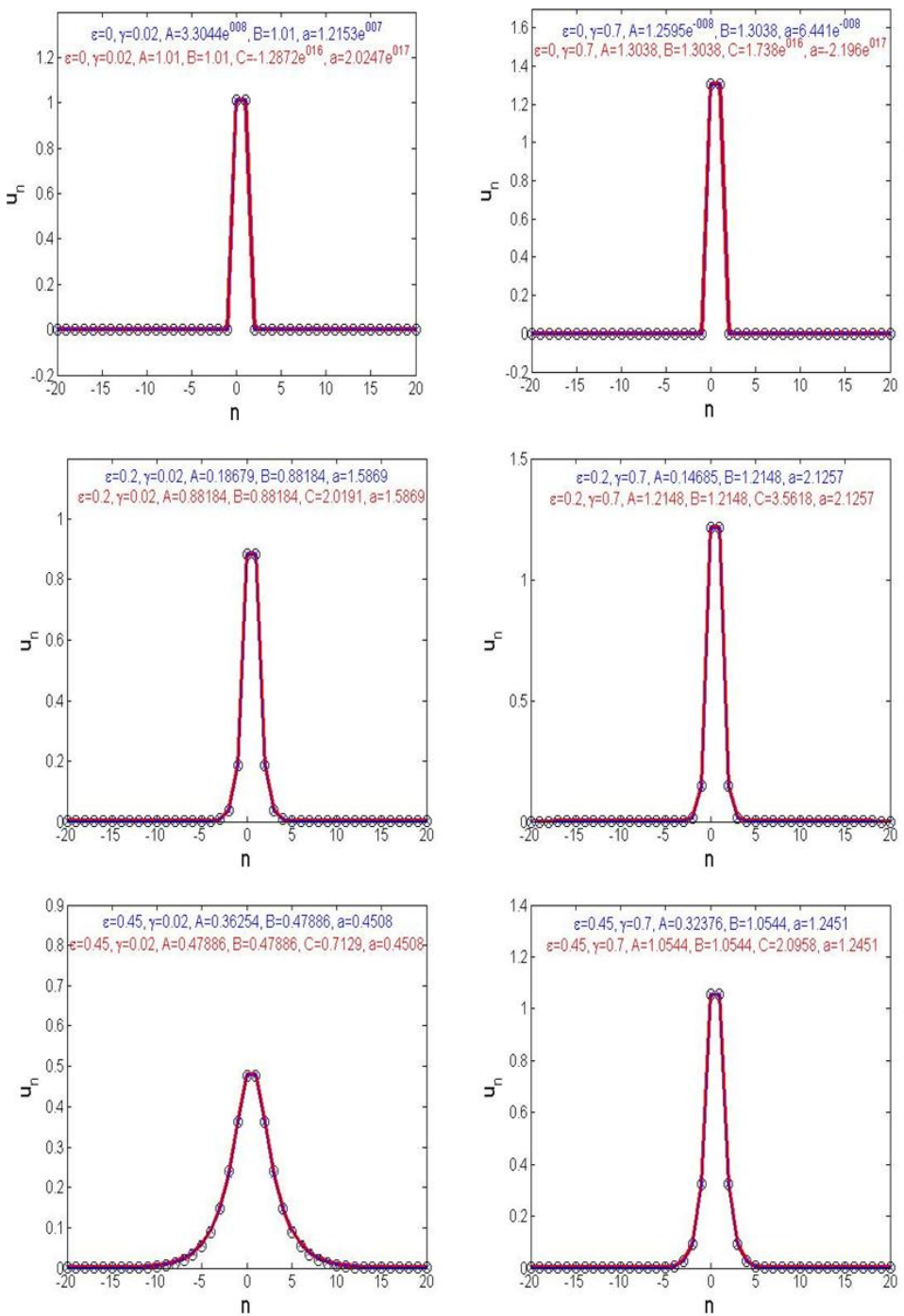

Gambar 4.1. Perbandingan solusi soliton intersite yang diperoleh secara numerik (garis-bulat) dengan aproksimasi variasional ansatz (1) (garis-silang) dan aproksimasi variasional ansatz (2) (garis-tebal) untuk beberapa nilai $\gamma$ dan $\varepsilon$.

[4] C. Chong, D. E. Pelinovsky, dan G. Schneider, 2011, On the validity of the variational approximation in discrete nonlinear Schrödinger equations, Physica D 241 : 115.

[5] M. Syafwan, 2012, Variational approximations for solitons in a parametrically driven discrete nonlinear Schrödinger equation, Prosiding Seminar Nasional Matematika, Universitas Andalas, ISBN 978-602-95343-2-0, pp. 52 - 58.

[6] D. Hennig, 1999, Periodic, quasiperiodic and chaotic localized solitons of a driven damped nonlinear lattice, Phys. Rev. E 59 : 1637.

[7] H. Susanto, Q. E. Hoq, dan P. G. Kevrekidis, 2006, Stability of discrete solitons 

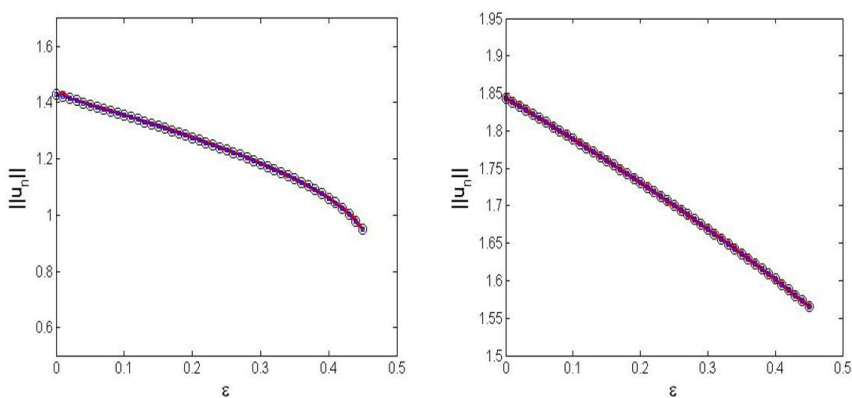

Gambar 4.2. Perbandingan antara nilai norm $l^{2}$ dari solusi numerik (bulat) dan solusi AV (kotakgaris tebal) sebagai fungsi terhadap $\varepsilon$ untuk $\gamma=0,02$ (kiri) dan $\gamma=0,7$ (kanan).

in the presence of parametric driving, Phys. Rev. E $74: 067601$.

[8] M. Syafwan, H. Susanto, dan S. M. Cox, 2010, Discrete solitons in elektromechanical resonator, Phys. Rev. E $81: 026207$.

[9] D. Hennig dan G. Tsironis, 1999, Waves transmission in nonlinear lattices, Phys. Rep. 307 : 333.

[10] P. G. Kevrekidis, K. O. Ramussen, dan A. R. Bishop, 2001, The discrete nonlinear Schrödinger equation: a survey of recent result, Internal. J. Modern Phys B $15: 28-33$.

[11] M. Syafwan, 2012, The Existence and Stability of Solitons in Discrete Nonlinear Schrödinger Equations, Disertasi Doktor, University of Nottingham. 